\title{
Attachment to Parents during Adolescence and Its Impact on Their
}

\section{Psychological and Social Adjustment}

\author{
Mrs. Shalini Singh ${ }^{1}$
}

\section{ABSTRACT:}

The notion of attachment has been defined in different ways, but something which is identical in all definitions is that attachment is an essential ingredient for normal Human Development.

From a developmental perspective, attachment theory has served as an important framework in understanding relationships throughout the lifespan. Attachment theory explains how individuals cope with conflict and assume various interpretations from the behaviors of others. From the experiences of early attachment relationships with a primary caregiver, the internal working model (IWM) becomes a mental representation of expectations and beliefs about the self in relation to others.

The parent-child relationship serves as a prototype for future relationships of the child. It is this first relationship that the child uses as a template to apply to future relationship experiences. In short, the qualities of early relationships predict later relationships, and success in later relationships takes root in lifespan development.

The present article provides a brief synopsis of the changes that occur during adolescence and describes what attachment is, why it continues to be important and how it is transformed during adolescence. It summarizes major findings on the impact of attachment on adolescent adjustment and discusses strategies for supporting healthy adolescent-parent attachment and also describes the secure and insecure attachments, patterns during adolescence towards parents and impact on their social \& Psychological adjustment.

Keywords: Adjustment, Adolescence, Attachment, Secure \& Insecure attachment, Caregiver, Psychological adjustment, Parent-child relationships,

In this research paper, we analyze the Attachment to parents during adolescence and its impact on their psychological and social adjustment.

To understand the attachment pattern during the adolescence; Firstly we understand the adolescence; Adolescence is the time between childhood and adulthood - between the ages of 1218 that is marked by growth and change, and physical and emotional development.

\footnotetext{
${ }^{1}$ Convener, Centre for Social Defence and Gender Studies, Rajasthan Police Academy, Jaipur
} 


\section{Attachment to Parents during Adolescence and Its Impact on Their Psychological and Social Adjustment}

The physical and mental changes are predictable, but that doesn't make this age group any easier to understand and communicate with. At the onset of adolescence children develop the ability to understand abstract concepts, question values, develop a more mature sense of identity and learn to establish personal relationships. The physical changes at this age are dramatic, as boys and girls gradually grow into men and women. Behavioral changes stem from the physical developments, which cause self-consciousness and sensitivity to body changes, as well as the insecurity that comes with comparison. Adolescents are often preoccupied with themselves, and this can cause anxiety when the changes in development are not always consistent with those of peers, and the periods of awkwardness don't happen to everyone at the same time or in the same way. Adolescence is a time when a child starts to become his own person, and the separation from parents begins. As adolescents begin to establish an individual identity, rebelliousness and peer influence may sometimes cause conflicts with parents. Positive adult role models can play an important role as young adults start to make their own decisions. Adolescents are not always aware of potential dangers surrounding them and their newfound individuality and freedom, and parental control and authority is often challenged. Knowing how to set limits and how to keep lines of communication open is crucial for parents at this stage. Adolescence follows a wellknown pattern, and part of accepting this is to acknowledge the fact that transition to adulthood is a challenging time for both parents and the adolescent.

According to Bowlby (1982), human beings are born with an innate psychobiological system (the attachment behavioral system) that motivates them to seek proximity to supportive others (attachment figures) in times of need. This system, which emerged over the course of evolution, accomplishes basic regulatory functions (protection from threats and alleviation of distress) and increases the likelihood of survival of human infants, who are born with immature capacities for locomotion, feeding, and defense.

Patterns of Attachments: Attachment can be divided into two main categories: secure and insecure attachments. Insecure attachment itself has three different types namely: insecureavoidant, insecure-ambivalent and insecure-disorganized.

\section{Secure Attachment}

In the context of the parent-child relationship earthy relationships with others in the future: (1) the establishment of a basic sense of trust in the world (2) the allowance for emotional regulation the expression of feelings, along with the underlying physiological patterning. When these two goals are successfully met, it is likely that the child will experience a satisfactory attachment relationship with his or her caregiver. Through this exploration of the environment, the child gains greater competence, acquiring greater independence in future experiences.

Insecure attachment during adolescence is related to fewer mental health problems, including lower levels of depression, anxiety and feelings of personal inadequacy. Insecurely attached adolescents are engage in substance abuse, antisocial and aggressive behavior, and risky sexual 


\section{Attachment to Parents during Adolescence and Its Impact on Their Psychological and Social Adjustment}

activity. Insecurely attached adolescents also miss-manage the transition to high school, and more negative relationships with family members. They demonstrate concern about loneliness and social rejection.

Adolescents-Parents relationships Adolescence is characterized by significant neurological, cognitive and socio-psychological development. With the advance of adolescence, the amount of time spent with parents. Nonetheless, parents continue to play a key role in influencing their adolescent's development. If conflict increases between Parents and children so adolescents moves to risky behavior as well as adolescents may see their parents as having turned harsh, controlling, and irrational both can feel baffled about what happened to the good old days of family harmony.

\section{IMPACT ON THEIR PSYCHOLOGICAL AND SOCIAL ADJUSTMENT;}

Self-esteem is how you feel about yourself. The development of a positive self-image and a healthy self-esteem is very important for making a successful transition from child to adult. If the bounding with parents is low so development during this age is law self-esteem. They are very isolated with society and indulged in risky behavior.

Peer pressures As children grow, they begin to spend more time with their friends and less time with their parents. As a result, friends can influence a child's thinking and behavior. This is the essence of peer pressure. If parents - child relationship is more attached so, peer pressure can be a positive influence-for example, when it motivates your child to do well in school, or to become involved in sports or other activities. On the other hand, peer pressure can be a negative influence for example, when it prompts your child to try smoking, drinking, using drugs, or to practice unsafe sex or other risky behaviors.

Adduction of tobacco, drugs and alcohol drug abuse is a serious problem that can lead to serious, even fatal, consequences. Research suggests that nearly 25 percent of adolescents (ages 12 to 17 ) have used drugs, with 16 to 18 as the peak age for drinking and drug abuse. Teens whose parents regularly communicate with them about the dangers of drugs have a decreased risk of using tobacco, alcohol or other drugs and those adolescents communication weak with their parents they very much close to drug \& tobacco.

Teens and sex Talking with your teenager is important to help him or her develop healthy attitudes toward sex and to learn responsible sexual behavior. Openly discussing sex with your teen also enables you to provide accurate information. After all, teens will learn about sex somewhere. But what they learn might not be true, and might not reflect the personal and moral values and principles you want your children to follow. In addition, teens need to understand the possible consequences of being sexually active including pregnancy and sexually transmitted diseases, as well as being emotionally hurt. 


\section{Attachment to Parents during Adolescence and Its Impact on Their Psychological and Social Adjustment}

Depression and suicide It is common for teens to occasionally feel unhappy. However, then he or she may be suffering from depression. There are many reasons why teenagers become unhappy. High-stress environments can lead to depression. Teens can develop feelings of worthlessness and inadequacy over school performance, social interaction, sexual orientation or family life. If friends, family or things that the teen usually enjoys don't help to improve his or her sadness or sense of isolation, there's a good chance that he or she is depressed. Often, depressed teens will display a striking change in their thinking and behavior, lose their motivation or become withdrawn.

More Parents sometimes adopted the wrong behavior towards because they want to be perfect child on every stapes like, education, Sports \& Games, Music, Schools, in Peer group ect. These all expectation of parents about your child is very unhealthy and harmful to adolescents which is; expecting the worst, Reading to more parenting books, Too much discipline in home, comparative study to other children's, Spent less time with children's, Any time bust to office work, less communication with adolescents on their issues. This is all beahviour impact to adolescents development sometimes they indulged the more wrong activity; Irritability or unusual emotionality or volatility, Sleep difficulty or nightmares, Inability to concentrate, Drop in grades or other functioning, Toileting or eating concerns. , Headaches or stomachaches, Unexplained fears or increased anxiety, Regression to earlier developmental levels, Isolation from family activities or peer relationships, Drug or alcohol experimentation.

Adolescence is the period of developmental transition between childhood and adulthood. It involves changes in personality, as well as in physical, intellectual and social development. During this time of change, teens are faced with many issues and decisions. The following addresses some of the key issues that can have an impact on a teen's Psychological social development.

- Understand that the child has grown up and respect the right to have an opinion different than yours.

- Give your teens some freedom to explore yourself. Don't expect him or her to do exactly as you say all of the time.

- Be Play with them for understanding them better

- Teens whose parents regularly communicate with them about the dangers of drugs have a decreased risk of using tobacco, alcohol or other drugs

- Give your child words of encouragement each day.

- Provide career guidance

- Teach your child how to avoid situations where others may be drinking, smoking or using drugs, and to choose friends who do not use these substances.

- Try to avoid telling your child what to do; instead, listen closely and you may discover more about the issues influencing your child's behavior. 


\section{Attachment to Parents during Adolescence and Its Impact on Their Psychological and Social Adjustment}

- Meet your child's monetary needs

- Encourage your child to become involved in extra-curricular activities at school, a church youth group, or other programs that provide opportunities for teens to gather and socialize in a fun and safe environment.

- Facilitate building of their esteem and self-confidence.

- Remember to point out the things your child does right, not just the mistakes.

- Is Positive towards this age as well as changes which is occurring during in this period.

- Encourage your child about decision-making and make it a point to recognize when he or she has made a good decision.

- Help your child learn to focus on his or her strengths by pointing out all of his or her talents and abilities.

- When disciplining your child, replace shame and punishment with positive reinforcement for good behavior. Shame and punishment can make an adolescent feel worthless and inadequate.

- Develop a close relationship with your child, and encourage open and honest communication. Children who have good relationships with their parents are more likely to seek a parent's advice about decisions or problems.

- Help your child understand what peer pressure is. The child will be better able to resist negative influences if he or she understands what's happening and why.

Today's young people, our children, belong to the most promising generation in the history of the world. They stand at the summit of the ages. They also stand at the crossroads of two great paths. One is the broader, well-travel the path that leads to mediocrity of mind and character, and to social decline. Parenting an adolescent presents a challenge that sometimes brings the best out of the parents and makes them better human beings. However, this is also a time which puts tremendous stress on the parents. Improper handling of adolescents can leave scars on the minds of the children which adversely affect the lifetime relationship between parent and child and may trigger unhealthy behaviors by both parties. Hence, it is very important that parents take all requisite steps in the right direction.

\section{REFERENCES:}

Bus, A. G., \& Van Ijzendoorn, M. H. (1988). Attachment and early reading: A longitudinal study. Journal of Genetic Psychology, 149(2), 199-210.

Coleman, P. K. (2003). Perceptions of parent-child attachment, social self-efficacy, and peer relationships in middle childhood. Infant and Child Development, 12, 351-368.

Bowlby, J. (1982). Attachment and loss: Vol. 1. Attachment (2nd ed.). New York: Basic

Bowlby, J. (1988). A secure base: Parent-child attachment and healthy human development. New York: Basic Books.

Kerns, K., Klepac, L., \& Cole, A. (1996). Peer relationships and preadolescents' perceptions of security in the child-mother relationship. Developmental Psychology, 32(3), 457-466. 


\section{Attachment to Parents during Adolescence and Its Impact on Their Psychological and Social Adjustment}

Heide, K. M., \& Solomon, E. P. (2006). Biology, childhood trauma, and murder: Rethinking justice. International Journal of Law and Psychiatry, 29, 220-233.

Henry, J. P. (1993). Psychological and physiological responses to stress: The right hemisphere and the hypothalamo-pituitary-adrenal axis, an inquiry into problems of human bonding. Integrative Physiological and Behavioral Science, 28, 369-387.

Jacobsen, T., \& Hofmann, V. (1997). Children's attachment representations: Longitudinal relations to school behavior and academic competency in middle childhood and adolescence. Developmental Psychology, 33(4), 703-710.

Kagan, J. (1981). The second year: The emergence of self awareness. Cambridge, MA: Harvard University Press.

Levy, T. M., \& Orlans, M. (2000). Attachment disorder as an antecedent to violence and antisocial patterns in children. In T. M. Levy (Ed.), Handbook of attachment interventions (pp. 1-26). San Diego, CA: Academic Press.

Lieberman, M., Doyle, A. B., \& Markiewicz, D. (1999). Developmental patterns in security of attachment to mother and father in late childhood and early adolescence: Associations with peer relations. Child Development, 70, 202-213.

Matas, L., Arend, R. A., Sroufe, L. A. (1978). Continuity of adaptation in the second year: The relationship between quality of attachment and later competence. Child Development, 49, 547-556.

O'Conner, E., \& McCartney, K. (2006). Testing associations between young children's relationships with mothers and teachers. Journal of Educational Psychology, 98(1), 8798.

Sroufe, L. A., Carlson, E., \& Shulman, S. (1993). Individuals in relationships: Development from infancy through adolescence. In D. C. Funder, R. Parke, C. Tomlinson-Keesey, \& K. Widaman (Eds.), Studying lives through time: Personality and development (pp. 315342), Washington DC: American Psychological Association.

Suess, G., Grossman, K. E., \& Sroufe, L. A. (1992). Effects of infant attachment to mother and father on quality of adaptation in preschool: From dyadic to individual organization of self. International Journal of Behavioral Development, 15, 43-65

Tomasello, M., \& Farrar, M. J. (1986). Joint attention and early language. Child Development, 57, 1454-1463.

Wartner, U. G., Grossmann, K., Fremmer-Bombik, E., \& Suess, G. (1994). Attachment patterns at age six in South Germany: Predictability from infancy and implications for preschool behavior. Child Development, 65, 1014-1027.

Wong, E., Wiest, D., \& Cusick, L. (2002). Perceptions of autonomy support, parent attachment, competence and self-worth as predictors of motivational orientation and academic achievement: An examination of sixth and ninth grade regular education students. Adolescence, 37(146), 255-266. 